Pacific Journal of Mathematic 


\title{
UNIMODALITY OF THE LÉVY SPECTRAL FUNCTION
}

\author{
Carol Alf and Thomas A. O'Connor
}

\section{A. Ya. Khinchin proved that if $\Phi$ and $\Psi$ are characteristic} functions and $\Phi(t)=t^{-1} \int_{0}^{t} \Psi(u) d u$, then the distribution function of $\Phi$ is convex on $(-\infty, 0)$ and concave on $(0,+\infty)$. A similar theorem is proved here for logarithms of infinitely divisible characteristic functions and their Lévy spectral functions.

Suppose $\Phi(t)$ is a characteristic function (ch.f) of a distribution function (df), $F$, so that $\Phi(t)=\int_{R} e^{i x t} d F(x)$. An application of Bochner's theorem (see [2]) shows that $\widetilde{\Phi}(t)=t^{-1} \int_{0}^{t} \Phi(u) d u$ is also a ch. $f$. Khinchin proved that $\widetilde{\Phi}$ is a ch. $f$ by constructing its df. In fact, he showed that a ch. $f$ is of the form $\widetilde{\Phi}$ if and only if its $\mathrm{df}$ is unimodal at 0 ; that is, the $\mathrm{df}$ is convex on $(-\infty, 0)$ and concave on $(0,+\infty)$. We shall prove a "unimodal theorem" for the function $\tilde{\phi}(t)=t^{-1} \int_{0}^{t} \phi(u) d u$ under the assumptions that $\Phi(t)$ is infinitely divisible and $\phi(t)=\ln \Phi(t)$. Johansen's characterization of infinitely divisible ch. fs. ([1], Theorem 2) insures that $\tilde{\phi}$, defined above, may also be written $\tilde{\phi}(t)=\ln \Psi(t)$, for some infinitely divisible ch. $f \Psi$, and hence provided the motivation for our work. To begin with, we state Lévy's form of infinitely divisible ch. fs. (See [2].)

THEOREM 1. A ch.f $\Phi$ is infinitely divisible if and only if $\phi(t)=\ln \Phi(t)$ may be uniquely represented as

$$
\phi(t)=i \mu t-\sigma^{2} t^{2}+f_{R}\left(e^{i x t}-1-\frac{i x t}{1+x^{2}}\right) d M(x)
$$

where $\mu \in R, \sigma^{2} \geqq 0$, and the function $M$ has the following properties:

(i) $M$ is defined on $R \backslash\{0\}$

(ii) $M$ is nondecreasing on $(-\infty, 0)$ and on $(0,+\infty)$ and is right continuous

(iii) $M(-\infty)=0=M(+\infty)$

(iv) $\int_{(-\varepsilon, \varepsilon)} x^{2} d M(x)$ is finite for all $\varepsilon>0$.

When (1) is in force, $M$ and $\left(\mu, \sigma^{2}, M\right)$ are respectively called the Lévy spectral function and the Lévy triple of $\Phi$. Moreover, every function which satisfies (i)-(iv) is a Lévy spectral function of 
some infinitely divisible ch. $\mathrm{f}$. The main result of this article is Theorem 2 below; two preliminary lemmas are proven first.

Lemma 1. For every Lévy spectral function, $M$, the following relations hold:

$$
\begin{aligned}
& \lim _{x \rightarrow+\infty} x \int_{x}^{+\infty} \frac{d M(z)}{z}=0=\lim _{x \rightarrow-\infty} x \int_{-\infty}^{x} \frac{d M(z)}{z} \\
& \lim _{x \rightarrow 0^{+}} x^{3} \int_{x}^{+\infty} \frac{d M(z)}{z}=0=\lim _{x \rightarrow 0^{-}} x^{3} \int_{-\infty}^{x} \frac{d M(z)}{z} .
\end{aligned}
$$

Proof. It is known that to each Lévy spectral function, $M$, there exists a df, $G$, and nonneagative number $c$ such that

$$
M(x)= \begin{cases}c \int_{-\infty}^{\infty} u^{-2}\left(1+u^{2}\right) d G(u) & \text { if } \quad x<0 \\ -c \int_{x}^{+\infty} u^{-2}\left(1+u^{2}\right) d G(u) & \text { if } \quad x>0 .\end{cases}
$$

Then, according as $x>1$ or $0<x<1$, we have $x \int_{x}^{+\infty} u^{-1} d M(u) \leqq$ $2 c x \int_{x}^{+\infty} u^{-1} d G(u)$ or $x^{3} \int_{x}^{+\infty} u^{-1} d G(u) \leqq 2 c x \int_{x}^{+\infty} u^{-1} d G(u)$. Similar statements hold for negative $x$. Now, if we apply Lemma 4.5.1 of [2] to the integrals involving $G$, the assertions of Lemma 1 follow at once.

Lemma 2. Let $M_{1}$ and $M_{2}$ be two Lévy spectral functions and assume they are related by

$$
M_{2}(x)= \begin{cases}-\int_{-\infty}^{x} \int_{-\infty}^{y} \frac{d M_{1}(z)}{z} d y & \text { if } \quad x<0 \\ -\int_{x}^{+\infty} \int_{y}^{+\infty} \frac{d M_{1}(z)}{z} d y & \text { if } \quad x>0 .\end{cases}
$$

Suppose $\phi(t)=i \mu t-\sigma^{2} t^{2}+\int_{R}\left(e^{i x t}-1-i x t /\left(1+x^{2}\right)\right) d M_{1}(x)$ where $\mu \in R, \sigma^{2} \geqq 0$. Then

$$
\begin{aligned}
t^{-1} \int_{0}^{t} \phi(u) d u= & i t\left((\mu / 2)+\int_{R} \frac{x^{3}}{\left(1+x^{2}\right)^{2}} d M_{2}(x)\right)-\left(\sigma^{2} t^{2} / 3\right) \\
& +\int_{R}\left(e^{i x t}-1-\frac{i x t}{1+x^{2}}\right) d M_{2}(x) .
\end{aligned}
$$

Proof. Let $T>0$ be fixed and define $K(u, x)=e^{\imath u x}-1-$ $i u x /\left(1+x^{2}\right)$. Then $K(u, x)=O\left(x^{2}\right)$ as $x \rightarrow 0$ uniformly for $|u| \leqq T$. Let $\eta>0$. Then 


$$
\begin{aligned}
& t^{-1} \int_{0}^{t} d u \lim _{\varepsilon \rightarrow 0^{+}} \int_{\varepsilon}^{+\infty} K(u, x) d M_{1}(x)=t^{-1} \int_{0}^{t} d u O\left(\int_{0^{+}}^{\eta} x^{2} d M_{1}(x)\right) \\
& \quad+t^{-1} \int_{\eta}^{\infty} \int_{0}^{t} K(u, x) d u d M_{1}(x)=O\left(\int_{0}^{\eta} x^{2} d M_{1}(x)\right)+\int_{\eta}^{+\infty} L(t, x) \frac{d M_{1}(x)}{x}
\end{aligned}
$$

where

$$
L(t, x)=\frac{e^{i t x}-1}{i t}-x-\frac{i t x^{2}}{2\left(1+x^{2}\right)} .
$$

Letting $\eta \rightarrow 0^{+}$, we have that

$$
t^{-1} \int_{0}^{t} \int_{0^{+}}^{+\infty} K(u, x) d M_{1}(x) d u=\int_{0^{+}}^{+\infty} L(t, x) \frac{d M_{1}(x)}{x} .
$$

A similar statement for the negative axis shows that

$$
\begin{aligned}
& t^{-1} \int_{0}^{t} \phi(u) d u=(i \mu t / 2)-\left(\sigma^{2} t^{2} / 3\right) \\
& \quad+\int_{R}\left(\frac{e^{i t x}-1}{i t}-x-\frac{i t x^{2}}{2\left(1+x^{2}\right)}\right) \frac{d M_{1}(x)}{x} .
\end{aligned}
$$

Now apply integration by parts to the integral in (4), to conclude that

$$
\begin{aligned}
t^{-1} \int_{0}^{t} \phi(u) d u= & (i \mu t / 2)-\left(\sigma^{2} t^{2} / 3\right)+\lim _{\varepsilon \rightarrow 0^{+}}\left[-\left.L(t, x) \int_{x}^{+\infty} z^{-1} d M_{1}(z)\right|_{x=\varepsilon} ^{+\infty}\right. \\
& +\int_{\varepsilon}^{+\infty} \frac{\partial L(t, x)}{\partial x} \int_{x}^{+\infty} z^{-1} d M_{1}(z) d z+\left.L(t, x) \int_{-\infty}^{x} z^{-1} d M_{1}(z)\right|_{x=-\infty} ^{-\varepsilon} \\
& +\int_{-\infty}^{-\varepsilon} \frac{\partial L(t, x)}{\partial x} \int_{-\infty}^{x} z^{-1} d M_{1}(z) d x \\
= & (i \mu t / 2)-\left(\sigma^{2} t^{2} / 3\right)+\int_{R} K(t, x) d M_{2}(x) \\
& +i t \int_{R} \frac{x^{3}}{\left(1+x^{2}\right)^{2}} d M_{2}(x) .
\end{aligned}
$$

The last equality follows by observing that $L(t, x) / x^{3}$ is bounded for $|t| \leqq T$ as $x \rightarrow 0$ and using Lemma 1 . This completes the proof of Lemma 2.

THEOREM 2. A necessary and sufficient condition for $\phi(t)$ to be the logarithm of an infinitely divisible ch. $\mathrm{f}$ whose Lévy spectral function is convex on $(-\infty, 0)$ and concave on $(0,+\infty)$ is that $\phi(t)$ may be written $\phi(t)=t^{-1} \int_{0}^{t} \psi(u) d u$, where $\psi$ is the logarithm of a certain infinitely divisible ch.f.

Proof. Suppose $\phi(t)=t^{-1} \int_{0}^{t} \psi(u) d u$ where $\psi$ and $\phi$ are as in the 
statement of the theorem and let $M_{1}$ and $M_{2}$ be the Lévy spectral functions of $\psi$ and $\phi$ respectively. Since the Lévy representation is unique, Lemma 2 shows that $M_{1}$ and $M_{2}$ are related by (3). Clearly $M_{2}$ is convex on $(-\infty, 0)$ and concave on $(0,+\infty)$ and so the sufficiency of the condition holds.

Conversely suppose a Lévy spectral function $M_{2}$ is given and assume further that $M_{2}$ is unimodal at 0 . Then we can write

$$
M_{2}(x)= \begin{cases}\int_{-\infty}^{x} p(u) d u & \text { if } \quad x<0 \\ -\int_{x}^{+\infty} p(u) d u & \text { if } \quad x>0\end{cases}
$$

where $p \geqq 0$ and is nondecreasing on $(-\infty, 0)$ and nonincreasing on $(0,+\infty)$. Define $M_{1}(x)=-\int_{-\infty}^{x} u d p(u)$ if $x<0$ and $M_{1}(x)=\int_{x}^{+\infty} u d p(u)$ if $x>0$. Then $M_{1}$ is also a Lévy spectral function and

$$
M_{2}(x)=\int_{-\infty}^{x} \int_{-\infty}^{y} d p(z) d y=-\int_{-\infty}^{x} \int_{-\infty}^{y} z^{-1} d M_{1}(z) d y
$$

if $x<0$, and similarly, $M_{2}(x)=-\int_{x}^{+\infty} \int_{y}^{+\infty} z^{-1} d M_{1}(z) d y$ if $x>0$. This shows that $M_{1}$ and $M_{2}$ are related by (3). So if $\phi$ has the Lévy triple $\left(\mu, \sigma^{2}, M_{2}\right)$, define

$$
\begin{aligned}
\psi(t)= & i t\left(2 \mu-2 \int_{R} \frac{x^{3}}{\left(1+x^{2}\right)^{2}} d M_{2}(x)\right)-3 \sigma^{2} t^{2} \\
& +\int_{R} e^{i t x}-1-\frac{i t x}{1+x^{2}} d M_{1}(x)
\end{aligned}
$$

By Lemma 2, $\phi(t)=t^{-1} \int_{0}^{t} \psi(u) d u$, and hence, the proof of Theorem 2. Some applications and consequences of Theorem 2 will be given.

(a) Suppose that a Lévy spectral function, $M$, and a df, $G$, are related by (2) for some $c \geqq 0$. From (2), it is clear that the (0)unimodality of $G$ entails that of $M$. The converse is not true; a counterexample is provided by the function $M(x)=c_{1}|x|^{-\alpha}$ or $c_{2} x^{-\alpha}$ according as $x<0$ or $x>0$, where $c_{1}, c_{2}>0$ and $0<\alpha<1$.

(b) Medgyessy ([3], Theorem 2.1) proved that if $M$ is symmetric and convex on $(-\infty, 0)$, then the original $\mathrm{df}$ is unimodal at 0 . Hence, combining our result with Khinchin's theorem on unimodality, one obtains that if $\Phi(t)$ is an infinitely divisible real ch.f and $\ln \Phi(t)=$ $t^{-1} \int_{0}^{t} \ln \Psi(u) d u$ for some infinitely divisible ch. $f \Psi$, then $\Phi(t)=t^{-1} \int_{0}^{t} \chi(u) d u$ for some ch. f $\chi(u)$.

( c ) Suppose $\phi(t)=i \mu t-b|t|^{\alpha}(1+(i \beta t /|t|) \omega(|t|, \alpha))$ corresponds 
to a stable law of index $\alpha$. (See [2], p. 136.) In this case

$$
\phi(t)=i \gamma t+c \tilde{\phi}(t)
$$

where $\gamma \in R, \quad c \geqq 0$, and $\tilde{\phi}(t)=t^{-1} \int_{0}^{t} \phi(u) d u$. Conversely suppose $\phi(t)=\ln \Phi(t)$ for some infinitely divisible ch. $f \Phi$ and for some $\gamma \in R$, $c \geqq 0$, (5) holds. Let $\left(\mu, \sigma^{2}, M\right)$ be the Lévy triple of $\Phi$. If $M=0$, then $\Phi$ is a normal ch. $\mathrm{f}$ and $c=3$. Assume $M$ is not identically zero. By Theorem 2, $M$ is convex on $(-\infty, 0)$ and concave on $(0,+\infty)$, and so there exists a nonnegative function $p(x)$ such that $p$ is nondecreasing on $(-\infty, 0)$, nonincreasing on $(0,+\infty)$, and such that

$$
M(x)=\left\{\begin{array}{lll}
\int_{-\infty}^{x} p(u) d u & \text { if } \quad x<0 \\
-\int_{x}^{+\infty} p(u) d u & \text { if } \quad x<0
\end{array}\right.
$$

Since the Lévy representation is unique, if (5) holds, the Lévy spectral functions of $\phi$ and $c \tilde{\phi}$ agree. Hence $M$ satisfies the identity

$$
M(x)= \begin{cases}-c \int_{-\infty}^{x} \int_{-\infty}^{y} z^{-1} d M(z) d y & \text { if } \quad x<0 \\ -c \int_{x}^{+\infty} \int_{y}^{+\infty} z^{-1} d M(z) d y & \text { if } \quad x>0\end{cases}
$$

In terms of $p,(6)$ reduces to

$$
p(x)= \begin{cases}-c \int_{-\infty}^{x} u^{-1} p(u) d u & \text { if } \quad x<0 \\ \int_{x}^{+\infty} u^{-1} p(u) d u & \text { if } \quad x>0 .\end{cases}
$$

Employing the uniqueness theorem for first order differential equations, it follows that $p(x)=p(-1)|x|^{-c}$ if $x<0$ or $p(1) x^{-c}$ if $x>0$. But since $\int_{R \backslash(-1,1)} p(x) d x$ and $\int_{\int_{(-1,1)}} x^{2} p(x) d x$ are both finite, we must have that $1<c<3$. This, in turn, forces $\sigma^{2}=0$. Combining this and the form of the Lévy spectral function for stable distributions, we see that (5) characterizes the stable laws.

ACKNOWLEDGMENT. We are very grateful for the many suggestions and comments of the referee. Because of these, Theorem 2 was proved in complete generality.

\section{REFERENCES}

1. S. Johansen, An application of extreme point methods to the representation of in- 
finitely divisible distributions, Z. Wahrscheinlichkeitstheorie verw. Gebiete, 5 (1966), 304-316.

2. E. Lukacs, Characteristic Functions, 2nd edition, Hafner, New York, 1970.

3. P. Medgyessy, On a new class of unimodal infinitely divisible distribution functions and related topics, Studia Sci. Math. Hungar., 2 (1967) 441-446.

Received April 20, 1976 and in revised form October 11, 1976.

UNIVERSITY OF LOUISVILLE

LOUISVILLE KY 40208 


\section{PACIFIC JOURNAL OF MATHEMATICS}

\section{EDITORS}

RICHARD ARENS (Managing Editor)

University of California

Los Angeles, CA 90024

R. A. BEAUMONT

University of Washington

Seattle, WA 98105

C. C. Moore

University of California

Berkeley, CA 94720

\section{J. DugundJI}

Department of Mathematics

University of Southern California

Los Angeles, CA 90007

R. Finn and J. Milgram

Stanford University

Stanford, CA 94305

\section{ASSOCIATE EDITORS}

\section{E. F. BECKENBACH}

B. H. NEUMANN

F. WoLF

K. YOSHIDA

\section{SUPPORTING INSTITUTIONS}

\author{
UNIVERSITY OF BRITISH COLUMBIA \\ CALIFORNIA INSTITUTE OF TECHNOLOGY \\ UNIVERSITY OF CALIFORNIA \\ MONTANA STATE UNIVERSITY \\ UNIVERSITY OF NEVADA \\ NEW MEXICO STATE UNIVERSITY \\ OREGON STATE UNIVERSITY \\ UNIVERSITY OF OREGON \\ OSAKA UNIVERSITY
}

\author{
UNIVERSITY OF SOUTHERN CALIFORNIA \\ STANFORD UNIVERSITY \\ UNIVERSITY OF HAWAII \\ UNIVERSITY OF TOKYO \\ UNIVERSITY OF UTAH \\ WASHINGTON STATE UNIVERSITY \\ UNIVERSITY OF WASHINGTON \\ AMERICAN MATHEMATICAL SOCIETY
}

The Supporting Institutions listed above contribute to the cost of publication of this Journal, but they are not owners or publishers and have no responsibility for its content or policies.

Mathematical papers intended for publication in the Pacific Jaurnal of Mathematics should be in typed form or offset-reproduced, (not dittoed), double spaced with large margins. Please do not use built up fractions in the text of your manuscript. You may however, use them in the displayed equations. Underline Greek letters in red, German in green, and script in blue. The first paragraph or two must be capable of being used separately as a synopsis of the entire paper. Items of the bibliography should not be cited there unless absolutely necessary, in which case they must be identified by author and Journal, rather than by item number. Manuscripts, in triplicate, may be sent to any one of the editors. Please classify according to the scheme of Math. Reviews, Index to Vol. 39. All other communications should be addressed to the managing editor, or Elaine Barth, University of California, Los Angeles, California, 90024.

The Pacific Journal of Mathematics expects the author's institution to pay page charges, and reserves the right to delay publication for nonpayment of charges in case of financial emergency

100 reprints are provided free for each article, only if page charges have been substantially paid. Additional copies may be obtained at cost in multiples of 50 .

The Pacific Journal of Mathematics is issued monthly as of January 1966. Regular subscription rate: $\$ 7200$ a year (6 Vols., 12 issues). Special rate: $\$ 36.00$ a year to individual members of supporting institutions.

Subscriptions, orders for back numbers, and changes of address should be sent to Pacific Journal of Mathematics, 103 Highland Boulevard, Berkeley, California, 94708.

PUBLISHED BY PACIFIC JOURNAL OF MATHEMATICS, A NON-PROFIT CORPORATION

Printed at Kokusai Bunken Insatsusha (International Academic Printing Co., Ltd.). 8-8, 3-chome, Takadanobaba, Shinjuku-ku, Tokyo 160, Japan.

Copyrit (C) 1975 by Pacific Journal of Mathematics Manufactured and first issued in Japan 


\section{Pacific Journal of Mathematics \\ Vol. 69, No. $2 \quad$ June, 1977}

Carol Alf and Thomas Alfonso O'Connor, Unimodality of the Lévy spectral

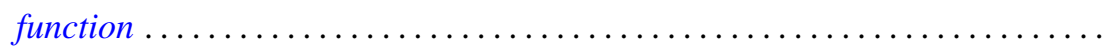

S. J. Bernau and Howard E. Lacey, Bicontractive projections and reordering of

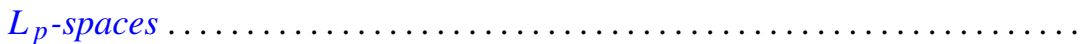

Andrew J. Berner, Products of compact spaces with bi-k and related spaces..... 303

Stephen Richard Bernfeld, The extendability and uniqueness of solutions of ordinary differential equations ...............................

Marilyn Breen, Decompositions for nonclosed planar m-convex sets ..........

Robert F. Brown, Cohomology of homomorphisms of Lie algebras and Lie

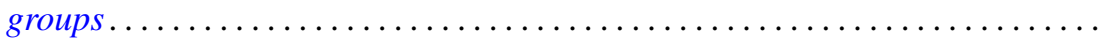

Jack Douglas Bryant and Thomas Francis McCabe, A note on Edelstein's iterative test and spaces of continuous functions ....................

Victor P. Camillo, Modules whose quotients have finite Goldie dimension ....... 333

David Downing and William A. Kirk, A generalization of Caristi's theorem with

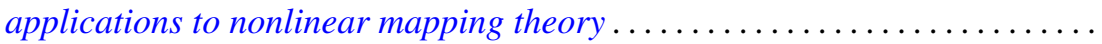

Daniel Reuven Farkas and Robert L. Snider, Noetherian fixed rings ...........

Alessandro Figà-Talamanca, Positive definite functions which vanish at

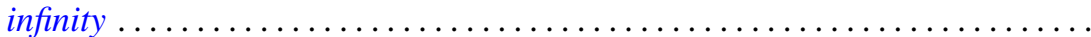

Josip Globevnik, The range of analytic extensions .................. 365

André Goldman, Mesures cylindriques, mesures vectorielles et questions de

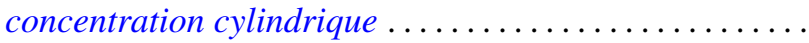

Richard Grassl, Multisectioned partitions of integers..........

Haruo Kitahara and Shinsuke Yorozu, A formula for the normal part of the

Laplace-Beltrami operator on the foliated manifold .... .

Marvin J. Kohn, Summability $R_{r}$ for double series .........

Charles Philip Lanski, Lie ideals and derivations in rings with involution ..

Solomon Leader, A topological characterization of Banach contractions . .

Daniel Francis Xavier O’Reilly, Cobordism classes of fiber bundles . .

James William Pendergrass, The Schur subgroup of the Brauer group . .

Howard Lewis Penn, Inner-outer factorization of functions whose Fourier series

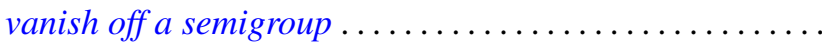

501

William T. Reid, Some results on the Floquet theory for disconjugate definite

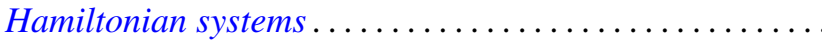

Caroll Vernon Riecke, Complementation in the lattice of convergence

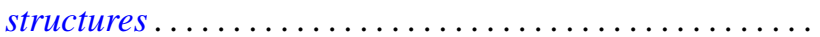

Louis Halle Rowen, Classes of rings torsion-free over their centers ......... 527

Manda Butchi Suryanarayana, A Sobolev space and a Darboux problem ....... 535

Charles Thomas Tucker, II, Riesz homomorphisms and positive linear maps.... 551

William W. Williams, Semigroups with identity on Peano continua ........... 557

Yukinobu Yajima, On spaces which have a closure-preserving cover by finite 